\title{
EL FLOEMA Y LA RUTA SIMPLÁSTICA DURANTE LA FORMACIÓN DE ORGANOS DE DEMANDA
}

\author{
THE PHLOEM AND THE SYMPLASTIC PATHWAY DURING \\ SINK ORGAN FORMATION
}

\author{
Esther Zúñiga-Sánchez ${ }^{1 *}$, Eleazar Martínez-Barajas', \\ Emma Zavaleta-Mejía ${ }^{2}$ y Alicia Gamboa-de-Buen ${ }^{3}$
}

\begin{abstract}
'Facultad de Química, Edificio E Laboratorio L-102, Universidad Nacional Autónoma de México (UNAM). Avenida Universidad 3000. 04510, Ciudad Universitaria, Delegación Coyoacán, CDMX, México. ²Postgrado de Fitosanidad, Colegio de Postgraduados, km 35.5 Carr. México-Texcoco. 56230, Montecillo, Edo. de México. In Instituto de Ecología, Laboratorio de Ecología Fisiológica, UNAM. Avenida Universidad 3000. 04510, Ciudad Universitaria, Delegación Coyoacán, CDMX, México.
\end{abstract}

*Autor para correspondencia (ezuniga@ecologia.unam.mx)

\section{RESUMEN}

El haz vascular de las plantas es un tejido altamente especializado, que permite tanto la comunicación entre los diferentes órganos como el transporte de diversas sustancias a larga distancia. El agua y minerales fluyen a través del xilema, mientras que por el floema se distribuyen agua, sacarosa, ácidos nucleicos, hormonas y proteínas principalmente. El floema presenta puentes estructurales denominados plasmodesmos, que permiten el transporte de moléculas de señalización relacionadas con la comunicación célula-célula. Los plasmodesmos pueden formar regiones especializadas denominadas campos o dominios simplásticos, los cuales se caracterizan por ser regiones semi-aisladas 0 aisladas por completo del resto de los tejidos. El tejido vascular participa también en la formación de nuevos órganos a partir de las células del periciclo tales como las raíces laterales, los nódulos, los sitios de alimentación de nematodos y los tubérculos. En esta revisión se discuten aspectos generales del tejido vascular, la importancia del floema como tejido de transporte molecular, su papel en la formación de órganos de demanda o vertedero de importancia, tales como semillas y raíces, así como en la formación de estructuras heterólogas como son los nódulos y los sitios de alimentación de nematodos (NSF), además de la influencia que ejercen ciertos patógenos durante su infección sobre el transporte de nutrientes a través de la ruta simplástica.

Palabras clave: Tejido vascular, floema, elementos de tubo criboso, células acompañantes, plasmodesmos, ruta simplástica, órganos de demanda.

\section{SUMMARY}

The vascular bundle of plants is a highly specialized tissue that allows both communication among different organs and the transport of various substances over long distances. Water and minerals flow through the xylem, while water, sucrose, nucleic acids and proteins are distributed through the phloem. The phloem presents structural bridges called plasmodesmata, involved in the transport of signalling molecules related to cell-to-cell communication. Plasmodesmata can form specialized regions known as symplastic fields or symplastic domains, which are characterized for being semi-isolated or completely isolated from the rest of the tissues. Vascular tissue also participates in the formation of new organs from pericycle cells such as lateral roots, nodules, nematode feeding sites and tubers. In this review we discuss general aspects of vascular tissue, the importance of phloem as a molecular transport tissue, its role in the formation of important sink organs such as seeds and roots, as well as in the development of heterologous structures as nodules and nematode feeding sites (NFS). In addition, the influence of certain pathogens during their infection over the nutrient transport through the symplastic pathway is discussed.

Index words: Vascular tissue, phloem, sieve elements, companion cells, plasmodesmata, symplasmic pathway, sink organs.

\section{INTRODUCCIÓN}

El desarrollo de un sistema vascular en las plantas promovió el establecimiento de una ruta eficiente por la que se transportan nutrientes, agua y diversas moléculas. Además de garantizar la comunicación entre los diferentes órganos de la planta, el sistema vascular también proporciona soporte mecánico. El tejido vascular está formado por dos tipos de tejidos, xilema y floema, ambos diferenciados a partir de las células del procámbium. El xilema transporta agua y minerales desde las raíces, mientras que el floema lleva a cabo el transporte masivo de agua y carbohidratos desde los sitios de síntesis; es decir, desde los órganos fuente hacia los órganos vertedero o demanda.

A través del floema también son distribuidos compuestos nitrogenados (aminoácidos y hormonas) y macromoléculas como RNA y proteínas que participan en la regulación del desarrollo y en la respuesta al ataque de patógenos (Kehr y Buhtz, 2008; Zhang et al., 2015). La capacidad del floema para transportar distintas moléculas ha sido empleada por ciertos virus y bacterias para diseminarse rápidamente en toda la planta. Estudios recientes han puesto de manifiesto el papel de las proteínas de algunos virus para establecer interacciones con proteínas de la planta para facilitar la distribución de su material genético por todas sus estructuras (Lazareva et al., 2016).

El desarrollo del sistema vascular está sometido a un control complejo en el que cambios en el balance hormonal y la participación de proteínas con función regulatoria 
resultan determinantes. En varias especies de gimnospermas, así como en dicotiledóneas, este proceso se lleva a cabo en dos fases que dan origen a la formación de los sistemas vascular primario y secundario. El sistema vascular primario se extiende por toda la planta (desde raíz, tallo y ramas laterales hasta hojas, flores y frutos) y su formación está determinada por la actividad del procámbium, un tejido que se diferencia en etapas tempranas del desarrollo del embrión.

El desarrollo del floema comienza antes que el del xilema y se diferencia cerca del meristemo apical. Las regiones apicales tienen un metabolismo muy activo ligado a la producción de compuestos fotosintéticos y a la generación de la energía necesaria para la división celular y la síntesis de la pared celular. La presencia del floema en esas zonas permite que los recursos sean distribuidos eficientemente en toda la planta. Este documento tiene como objetivo describir algunos aspectos generales del desarrollo del tejido vascular primario y enfatizar la importancia del floema como un sistema de transporte de moléculas señalizadoras, así como describir la importancia del transporte simplástico vía plasmodesmos, cuya función está relacionada con la formación y el crecimiento de diversas estructuras de demanda de relevancia ecológica.

\section{El papel de las hormonas en la formación y diferenciación celular en el haz vascular}

Las auxinas, las citocininas y los brasinoesteroides son hormonas vegetales que juegan un papel determinante tanto en el desarrollo como en el establecimiento de la identidad de las células que forman el sistema vascular. En el Cuadro 1 se resume el papel que juegan distintas hormonas durante el establecimiento y la diferenciación del haz vascular. Se han descrito también proteínas de importancia primordial durante el desarrollo del haz vascular, entre las que destacan los factores de transcripción PHABULOSA (PHB), REVOLUTA (REV) y CORONA (AtHB15), los cuales contribuyen al establecimiento de la polaridad adaxia/abaxial en órganos laterales y del brote (llegems et al., 2010).

El factor de transcripción de tipo Myb ALTERED PHLOEM DEVELOPMENT (APL) está involucrado en la diferenciación de los elementos de tubo criboso y de sus células acompañantes, además de participar en el establecimiento de los límites de crecimiento de las células del xilema (Bonke et al., 2003). Por su parte, LONESOME HIGHWAY (LHW) codifica para un factor transcripcional del tipo bHLH, cuyas mutaciones eliminan la simetría bilateral del haz vascular y reducen el número de células del polo

Cuadro 1. El papel hormonal en el desarrollo del haz vascular.

\begin{tabular}{|c|c|c|c|}
\hline $\begin{array}{l}\text { Nombre de la } \\
\text { hormona }\end{array}$ & $\begin{array}{l}\text { Papel que desempeña durante el } \\
\text { desarrollo del haz vascular }\end{array}$ & Genes involucrados & Referencias \\
\hline Auxinas & $\begin{array}{l}\text { Promoción del patrón del haz vascular. } \\
\text { Establecimiento del procámbium y de la } \\
\text { simetría del haz vascular desde etapas } \\
\text { embriogénicas. }\end{array}$ & $\begin{array}{l}\text { Kanadi1-4 (KAN), PIN-Formed, } \\
\text { (PIN1, PIN3, PIN7), Monopteros } \\
\text { (MP). }\end{array}$ & $\begin{array}{l}\text { Kerstetter et al., } \\
2001 \text {; Berleth y } \\
\text { Mattsson, 2000; } \\
\text { Hardtke y Berleth, } \\
\text { 1998. }\end{array}$ \\
\hline Citocininas & $\begin{array}{l}\text { Proliferación, determinación y } \\
\text { mantenimiento de la identidad de } \\
\text { las células del procámbium y del } \\
\text { protoxilema. }\end{array}$ & $\begin{array}{l}\text { Wooden Leg (WOL), Arabidopsis } \\
\text { Histidine Phosphotransfer Protein } \\
6(\text { AHP6), Arabidopsis Histidine } \\
\text { Kinase (AHK2, AHK3 y AHK4), } \\
\text { Cytokinin Oxidase }(C K X), \text { Cytokinin } \\
\text { Independet } 7(C K I 7) \text {. }\end{array}$ & $\begin{array}{l}\text { Bishopp et al., 2011; } \\
\text { Hejátko et al., 2009, } \\
\text { Mähönen et al., } \\
\text { 2006, } 2000 .\end{array}$ \\
\hline Brasinoesteroides & $\begin{array}{l}\text { Diferenciación provascular, } \\
\text { mantenimiento de las proporciones } \\
\text { adecuadas de xilema:floema. Polaridad } \\
\text { del haz vascular. Promoción de la } \\
\text { diferenciación del xilema, especificación } \\
\text { de elementos traqueales. }\end{array}$ & $\begin{array}{l}\text { BR-insensitive } 1 \text { BRI1, BRL } 1, B R L 3 \text {, } \\
\text { Cotyledon Vascular Pattern } 1 \\
\text { (CVP1). }\end{array}$ & $\begin{array}{l}\text { Caño-Delgado et al., } \\
2004 .\end{array}$ \\
\hline Giberelinas & $\begin{array}{l}\text { Expansión de las células del xilema. } \\
\text { El balance de las GA con el etileno, } \\
\text { afecta la actividad de las células del } \\
\text { procámbium. }\end{array}$ & $\begin{array}{l}\text { GA 20-oxidase1, GA 3-oxidase, } \\
\text { DELLA-like, GIP-like1. }\end{array}$ & Ragni et al., 2011. \\
\hline
\end{tabular}


del xilema y del polo del floema (Lehesranta et al., 2010; Ohashi-Ito et al., 2013; Ohashi-Ito et al., 2014). El complejo transcripcional regulado por auxinas TARGET OF MONOPTEROS5/LONESOME HIGHWAY (TMO5/LHW) promueve las divisiones celulares periclinales que generan el patrón del haz vascular, a través de la regulación de la expresión de genes involucrados en la biosíntesis de citocininas (De Rybel et al., 2014).

La proliferación de las células de procámbium, mediante divisiones celulares orientadas, genera un arreglo del haz vascular con células del xilema en el centro del haz vascular y floema en la periferia; este proceso y la diferenciación de las células del xilema son regulados por una proteína con abundantes motivos ricos en leucinas RLK PHLOEM INTERCALATED WITH XYLEM (PXY), la cual controla la orientación y división de las células del procámbium. Plantas mutantes de esta proteína presentan células del floema adyacentes e intermezcladas con células del xilema (Bryan et al., 2012; Fisher y Turner, 2007).

\section{Estructura y tipos celulares del floema}

Los elementos de tubo criboso y sus células acompañantes son los tipos celulares más importantes del floema en angiospermas; sin embargo, también se encuentran células del parénquima y fibras, las cuales en ciertas especies juegan un papel importante en la producción, almacenamiento y liberación de metabolitos diversos como almidones y taninos, además pueden contener cristales.

Los elementos de tubo criboso son células vivas alargadas y altamente modificadas, con paredes interconectadas que les permiten funcionar como tubos conductores. Estas paredes son denominadas áreas cribosas, las cuales se caracterizan por la presencia de abundantes poros con depósitos de calosa que permiten la continuidad citoplásmica que interconecta una célula con sus vecinas. Cuando las áreas cribosas se ubican en las paredes transversales que se encuentran en el extremo de las células se denominan placas cribosas y presentan poros cuyo diámetro puede variar de 1 a $14 \mu \mathrm{m}$, según la especie (Esau y Cheadle, 1959; Mullendore et al., 2010).

Las placas cribosas se originan a partir de la acumulación masiva de calosa en las paredes celulares de los canales especializados denominados plasmodesmos. Posteriormente, la calosa se desintegra y deja los poros abiertos (Lee y Lu, 2011). Bajo ciertas condiciones, tales como la formación de heridas por acción mecánica, cambios químicos y estrés fisiólógico, puede presentarse acumulación de calosa en la superficie de las placas cribosas tan abundante que provoca obstrucción de la superficie de las áreas cribosas. Esto permite el aislamiento de la región que ha sido afectada del resto de la planta e impide la pérdida de solutos o la diseminación de un patógeno en el caso de una infección (van Bel, 2002; Xie y Hong, 2011).

Como consecuencia de su alto grado de especialización estructural para hacer más eficiente el transporte de savia, como es la pérdida del núcleo y en el caso de las gimnospermas su reducción (Lough y Lucas, 2006), la pérdida de los ribosomas y del citoesqueleto, así como la redistribución parietal del retículo endoplásmico, las células del tubo criboso son incapaces de realizar muchas de sus funciones vitales y son altamente dependientes de las células acompañantes (en inglés companion cells, CC). Las CC proveen a las células cribosas aledañas de nutrientes y de macromoléculas, de modo que se les considera parte esencial de las unidades funcionales del floema. Las CC y los elementos de tubo criboso están comunicados por conexiones simplásticas (a través de plasmodesmos) y apoplásticas que contribuyen en el transporte de metabolitos y proteínas (enzimas, estructurales, transportadores, etc.).

La unidad funcional elemento criboso-célula acompañante (SE-CC, por sus siglas en inglés) también está Conectada por plasmodesmos con las células del parénquima del floema (van Bel et al., 2002). En función del tipo de tejido y de la etapa del desarrollo, estos plasmodesmos tienen la capacidad de modificar el límite de exclusión del tamaño de las moléculas que pueden transportar (en inglés size exclusion limit, SEL). En la savia del floema de distintas especies tales como Oryza sativa, Triticum spp., Ricinus communis y en cucurbitáceas se han identificado al menos 200 proteínas entre 10 a 40 kDa y muchas más entre 60 y $70 \mathrm{kDa}$. Se ha reportado que a lo largo del floema existe un intercambio constante de proteínas entre los elementos de tubo criboso y sus células acompañantes. Esto sugiere que algunas de las proteínas presentes en la savia del floema son parte de los mecanismos de señalización a larga distancia que coordinan la participación de los órganos en respuesta a distintos procesos fisiológicos (Turgeon y Wolf, 2009).

De acuerdo con su función y ubicación se consideran tres tipos de floema: el colector que se localiza en las venas menores de los órganos fuente, el transportador que se ubica a lo largo de la ruta desde el órgano fuente hasta el órgano de destino o demanda, y el floema de liberación localizado muy cercanamente al órgano destino. Estos tres tipos de floema presentan diferencias en la concentración de los solutos en la savia como consecuencia de la toma y descarga de nutrientes a lo largo de la ruta (van Bel, 2003). 


\section{Los plasmodesmos y la formación de dominios y campos simplásticos}

Los plasmodesmos se definen como puentes citoplásmicos que conectan las paredes de células vecinas, delimitados por las membranas citoplasmáticas, y además están asociados con el retículo endoplásmico el cual forma un continuo entre las células (Burch-Smith et al., 2011; Lucas et al., 1993) (Figura 1).

De acuerdo con su origen, los plasmodesmos han sido clasificados en primarios y secundarios. Los plasmodesmos primarios se forman durante la división celular, cuando el retículo endoplásmico queda atrapado en la lámina media de las células en división durante la deposición de la pared celular mediada por el aparato de Golgi. Los plasmodesmos secundarios se originan después de la citocinesis y pueden formarse a partir de un plasmodesmo simple, o bien por la formación de novo de un plasmodesmo. Independientemente de su origen, los plasmodesmos también pueden ser simples o ramificados (Burch-Smith et al., 2011). La frecuencia de plasmodesmos, primarios o secundarios, varía entre tejidos.

Los plasmodesmos median el transporte de macromoléculas y proteínas de la ruta no autónoma, que incluyen factores de transcripción involucrados en el desarrollo y la determinación celular, así como RNA y complejos de proteínas-RNA en respuesta a ataque por patógenos.

Los plasmodesmos presentan tres estados funcionales básicos: abierto, cerrado y dilatado, que se diferencian por su SEL. La dinámica de los cambios en este atributo durante el crecimiento y el desarrollo de diferentes estructuras de la planta se ha estudiado mediante técnicas de microscopía y proteínas de movimiento

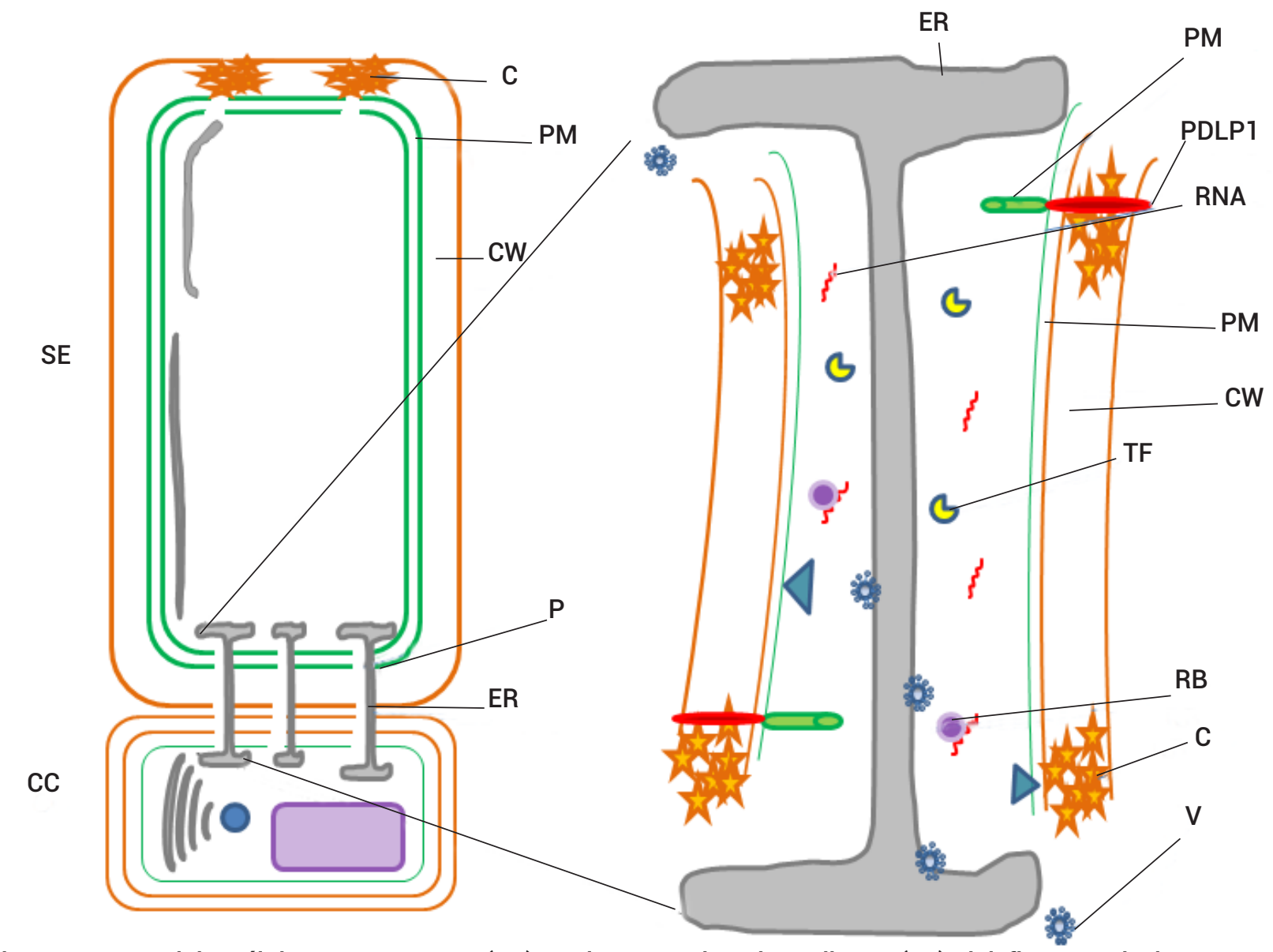

Figura 1. Complejo célula acompañante (CC) y elemento de tubo criboso (SE) del floema. El elemento criboso es funcionalmente dependiente de la CC, entre ellas se establece una estrecha comunicación mediada por plasmodesmos (P). Los plasmodesmos son estructuras delimitadas por las paredes celulares (CW) con depósitos de calosa (C) y estructuralmente atravesados por el retículo endoplásmico (ER). A través de ellos pueden ser transportadas diversas moléculas tales como azúcares, factores transcripcionales (TF), RNAs, ribonucleoproteínas (RB), elicitores y viriones (V), entre otras. 
(MP) de diferentes virus [del mosaico del tabaco (Nicotiana tabacum L. ) (TMV), de la calabaza (Cucurbita maxima) (CMV) o de la papa (Solanum tuberosum) (PVX)]. Algunas proteínas de estos virus son capaces de incrementar el límite de exclusión molecular de los plasmodesmos hasta en 15 kDa, lo que facilita la diseminación de los virus ( $\mathrm{Ha}$ ywood et al., 2002).

La dinámica de cambios en la apertura del SEL determina el establecimiento de campos simplásticos, que se definen como células comunicadas citoplásmicamente que ejecutan programas de desarrollo comunes (Lee y Lu, 2011; Lough y Lucas, 2006). Algunos de los factores de transcripción involucrados en la determinación y el desarrollo de los meristemos apicales del brote, como LEAFY (LFY) FLOWERING LOCUS T (FT) en Arabidopsis, y DEFICIENS (DEF), GLOBOSA (GLO) y FLORICAULA (FLO) en Antirrhinum majus (Burch-Smith et al., 2011), son transportados a través de los plasmodesmos.

Distintas aproximaciones se han empleado con el fin de conocer la composición de los plasmodesmos (Fernandez-Calvino et al., 2011). Su pared celular se caracteriza por ser rica en pectina (familia de polisacáridos formados principalmente por residuos de ácido glucurónico con unión a-1,4) y puede presentar depósitos abundantes de calosa (polímero constituido de glucanos con uniones tipo $\beta-1,3)$. No se ha establecido la función de las pectinas, pero se ha determinado que al constreñir físicamente el orificio de apertura la calosa puede regular el SEL a largo plazo.

Estudios proteómicos han establecido que tanto las membranas como las paredes celulares de los plasmodesmos son peculiares (Fernandez-Calvino et al., 2011). La proteína PDCB1 es de 21 kDa, de la familia de proteínas de unión a calosa (PDCB, callose binding protein) que se localiza en la membrana plasmática del cuello del plasmodesmo, a la que se ancla a través de un GPI (glicosil fosfatidil inositol), lípido que reconoce ciertas regiones de la membrana plasmática.

La sobreexpresión de la proteína PDCB1 produce un incremento en la concentración de calosa, lo que correlaciona con un bloqueo en el transporte (Simpson et al., 2009). La enzima $\beta-1,3$ glucanasa (también con un motivo de anclaje a GPI), y las RGP (reversibly glycosylated proteins) afectan la acumulación de calosa alrededor de los plasmodesmos (Sagi et al., 2005). La sobreexpresión de las RGP de Arabidopsis en tabaco (Nicotiana tabacum L.) da como resultado plantas con clorosis y escaso crecimiento en las hojas que funcionan como fuente, posiblemente como consecuencia de una disminución en el flujo de nutrientes ocasionada por la acumulación de calosa en los plasmodesmos de las células epidérmicas de las hojas fuente
(Lee y Lu, 2011; Zavaliev, 2010).

Otras proteínas, como las PDLP1 (plasmodesmata-located-proteins 1) también contribuyen a modular el tráfico a través de los plasmodesmos; en el caso del transporte de virus éste se ve favorecido por la interacción de las MP del virus con las PDLP (Amari et al., 2010). Las REMORINAS (REM) son una familia de proteínas específicas de plantas vasculares asociadas a regiones de la membrana celular denominadas balsas lipídicas. Se ha considerado a las balsas lipídicas, las cuales son especialmente abundantes en plasmodesmos, como sitios de señalización de proteínas específicas implicadas en la regulación del establecimiento de interacciones bióticas entre la planta y distintos patógenos como virus y bacterias (Mongrand et al., 2010; Xu y Jackson, 2010). La presencia de esta gran diversidad de proteínas en los plasmosdesmos, cuya función principal es regular el transporte de diversas moléculas, resulta ser de gran relevancia evolutiva en plantas. Según Lee (2014) y Benitez-Alfonso et al. (2009), la alteración del transporte simplástico generalmente produce fenotipos letales, lo que apoya la hipótesis de que el desarrollo de los plasmodesmos es un evento evolutivo crucial para el éxito de las plantas superiores.

Un dominio simplástico es un grupo de células interconectadas entre sí, pero aisladas completamente del resto de los tejidos, mientras que los campos simplásticos se definen como grupos de células interconectadas y parcialmente aisladas del resto de los tejidos (Rinne y van der Schoot, 1998). En Arabidopsis se ha descrito la existencia de campos simplásticos en el ápice y en la epidermis de la raíz, en el embrión, en las semillas y en el tejido que rodea a los gametofitos femenino y masculino.

Los plasmodesmos localizados dentro del mismo campo simplástico modulan el paso de moléculas señalizadoras y permiten de esta manera la formación de gradientes morfogénicos necesarios durante el desarrollo de ciertos tejidos. En ocasiones, el aislamiento simplástico es determinante para el desarrollo de un tipo celular como el pelo radical, la célula oclusiva del estoma, la célula madre de la microspora, y de la megaspora femenina, la cual también se aísla del resto de las células del óvulo.

Los dominios simplásticos relacionados con la carga y la descarga del floema se han estudiado en Arabidopsis mediante la expresión de la proteína GFP (green fluorescent protein) bajo el control del promotor del transportador de sacarosa AtSUC2, cuya expresión es específica de las células acompañantes. No obstante el gran tamaño de la proteína GFP (27 kDa), en el ápice de la raíz se distribuye simplásticamente vía los plasmodesmos localizados en los elementos de tubo criboso del protofloema, 
hacia todos los tipos celulares. La señal de la GFP puede ser observada en células corticales subepidérmicas, epidérmicas y por debajo de las células del protofloema. Cuando GFP se expresa como proteína de fusión con un peso molecular mayor a $27 \mathrm{kDa}$, la señal se confina al haz vascular (Stadler et al., 2005b).

En la etapa embrionaria y durante la formación de la semilla en Arabidopsis se establecen dominios simplásticos involucrados en el transporte de nutrientes liberados desde el extremo funicular hacia el floema del embrión en desarrollo. De acuerdo con las observaciones realizadas por Stadler et al. (2005a), el tegumento externo permite el movimiento de nutrientes y macromoléculas como un continuo o extensión simplástica del floema funicular. Sus análisis también sugieren que el transporte de nutrientes al embrión en estado globular ocurre vía simplástica desde el suspensor. Durante la etapa de torpedo, el SEL de los plasmodemos que conectan al embrión con el suspensor se reduce; por tanto, el embrión constituye un único dominio simplástico en esta etapa en Arabidopsis (Stadler et al., 2005a) (Figura 2).

\section{Formación de órganos de demanda. El caso de las semillas}

La formación y crecimiento de las semillas en el caso de las espermatofitas (plantas con semilla), es un proceso con grandes implicaciones en su ciclo de vida, y el desarrollo de las semillas de especies de importancia agronómica tiene además un impacto económico considerable. Como órganos de demanda, el tamaño y desarrollo adecuado de las semillas depende en gran medida de un transporte eficiente de nutrientes desde las hojas fuente hacia el tejido embrionario, así como de su distribución y su asignación.

El desarrollo de la semilla puede dividirse en dos etapas principales, la morfogénesis y la maduración. Durante la maduración se llevan a cabo procesos vitales como el crecimiento del embrión y la acumulación de las sustancias de reserva. Para que esto ocurra es necesario que el carbono y el nitrógeno transportados se almacenen principalmente en forma de lípidos, almidón y proteínas. La sacarosa requerida para la síntesis de dichos compuestos es transportada por el floema desde las hojas fuente hasta el funículo y desde el tegumento externo hacia el interno, y de éste hacia al suspensor (Stadler et al., 2005a); sin embargo, se ha comprobado que previo a la antesis ocurre un cambio en el tipo de transporte de sacarosa hacia las células primordiales de los óvulos y éste pasa a ser apoplástico. Una vez ocurrida la antesis, el transporte regresa a ser simplástico (Werner et al., 2011). El transporte de sacarosa desde el floema hacia el apoplasto es facilitado por los transportadores de sacarosa localizados en la membrana plasmática denominados SWEET, los cuales se encuentran ampliamente conservados en eucariontes,

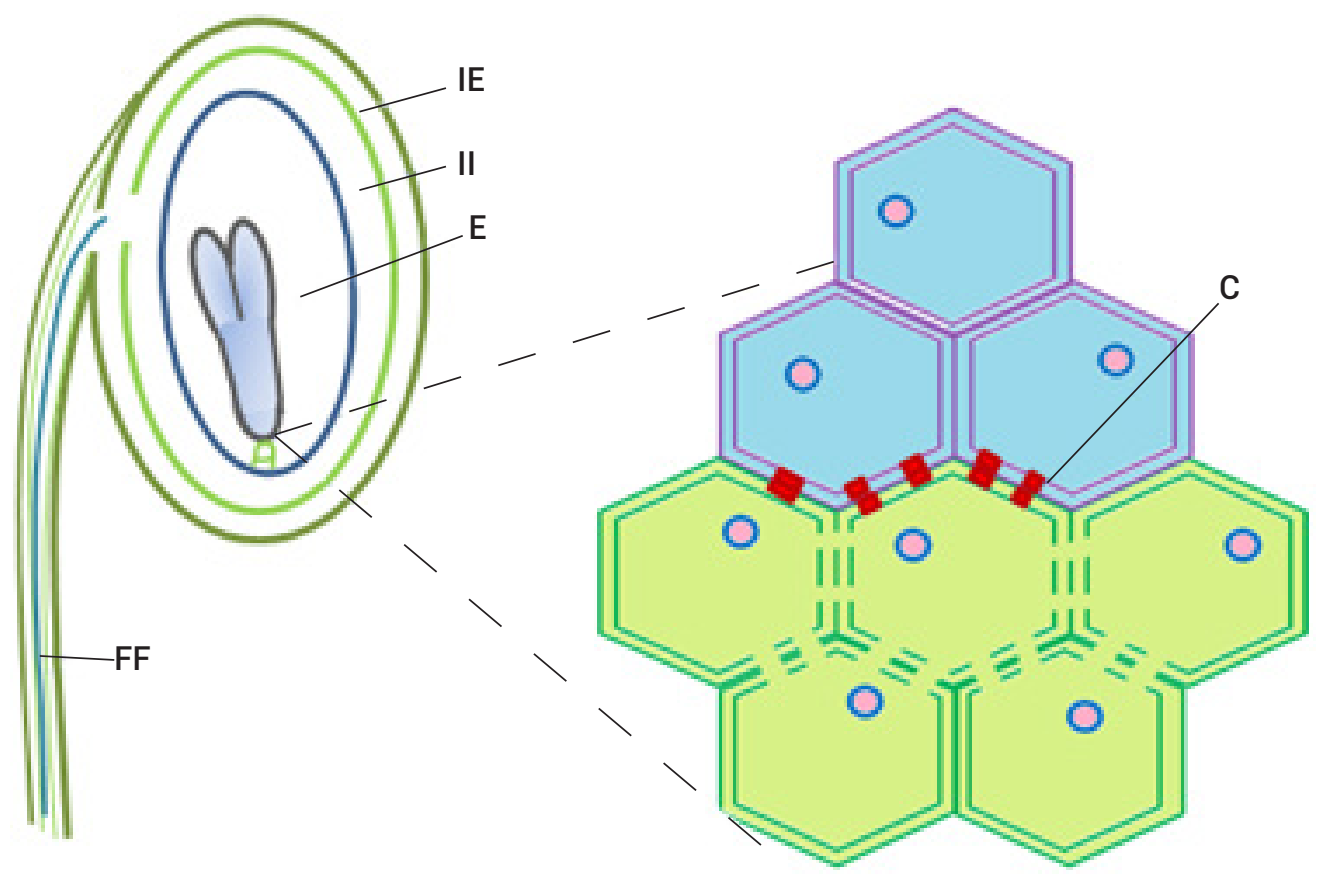

Figura 2. Formación de un dominio simplástico durante el desarrollo embrionario. El límite de exclusión molecular (SEL) de los plasmodesmos se reduce durante la etapa de torpedo en Arabidopsis thaliana aislando simplásticamente al embrión. IE: tegumento externo, II: tegumento interno, E: endospermo, C: calosa, FF: floema funicular. 
aunque este transporte de sacarosa también se atribuye a los transportadores de tipo simporte de sacarosa $/ \mathrm{H}^{+}(\mathrm{SUC})$.

Se ha descrito el papel de los diferentes miembros de la familia de transportadores SWEET, por ejemplo SWEET11, 12 y 15, que son determinantes en el flujo de sacarosa desde los tegumentos hacia el apoplasto y el embrión. Las plantas dobles mutantes de Arabidopsis atsweet 7 y 12 muestran un fenotipo menos severo, debido posiblemente a la redundancia funcional, en la reducción en el tamaño del embrión, con respecto a las triples mutantes atsweet 17; 12 y 15, las cuales muestran retraso en el desarrollo del embrión, una reducción en el peso de la semilla y en el contenido de lípidos. Las mutantes simples atsuc2 no producen semillas viables (Liu et al., 2016).

Otro tipo de proteínas transmembranales cuya expresión es importante para el desarrollo adecuado de las semillas son las denominadas SUT, familia de cotransportadores sacarosa $/ \mathrm{H}^{+}$, localizados en el tonoplasto y en la membrana plasmática, capaces de transportar sacarosa principalmente en aquellas especies cuya carga del floema es vía apoplasto. Una vez que la sacarosa se encuentra en el apoplasto es transportada hacia el complejo elemento criboso-célula acompañante (SE-CC, por sus siglas en inglés) a través de estos transportadores de influjo y puede ser almacenada en dicho complejo celular en contra de un gradiente de concentración.

Es posible que los transportadores SWEET jueguen un papel determinante en el transporte de sacarosa en distintas especies en plantas, en coordinación con los transportadores SUC/SUT; sin embargo, esto aún no ha sido estudiado (Chen et al., 2015). La regulación de la expresión y la localización celular de este tipo de transportadores puede ser modificada durante la invasión por patógenos, como se ha demostrado en distintas especies. Dichas alteraciones intervienen en la redistribución de los nutrientes hacia las zonas donde ha ocurrido la infección (Chen et al., 2015).

El transporte de nitrógeno también es determinante durante la formación del fruto y las semillas. Existen dos cuellos de botella descritos durante el transporte del $\mathrm{N}$ a larga distancia; el primero está relacionado con la carga de los aminoácidos en el floema de las hojas, y el segundo con la entrada al embrión. Se ha propuesto que una familia de permeasas ácidas (AAP) está asociada con la carga de los aminoácidos, pues su localización en el floema de hojas así lo sugiere. En plantas de chícharo (Pisum sativum L.), una vez que los aminoácidos Ilegan a las células del floema son transportados vía simplástica hacia la pared de las vainas y la cubierta de las semillas a través de los plasmodesmos. Posteriormente los aminoácidos se transportan apoplásticamente a través de proteínas similares a las descritas como SIAR1 (Siliques Are Red1). Los análisis de expresión de estas proteínas sugieren su participación en el transporte de aminoácidos hacia células epidérmicas del embrión, las cuales funcionan como células de transferencia (Zhang et al., 2015).

\section{Raíces laterales, nódulos y tubérculos}

Al igual que las semillas, las raíces laterales de Arabidopsis son consideradas un órgano de demanda por excelencia. La formación de una nueva raíz lateral es un proceso coordinado que implica divisiones celulares asimétricas a partir del periciclo. El periciclo constituye la región celular más externa del cilindro central o haz vascular y está organizado en una única capa de células con formas regulares conectadas a través de sus paredes tangenciales (Dolan et al., 1993; Parizot et al., 2008).

Existen diferencias entre las células del periciclo según su función y su ubicación, por lo que han sido denominadas células del periciclo adyacentes al polo del xilema y las adyacentes al polo del floema (Dubrovsky et al., 2000; Laplaze et al., 2005; Parizot et al., 2008; Wright y Oparka, 1997). En Arabidopsis las células del periciclo del polo del xilema tratadas con ácido a-naftalenacético (NAA), un precursor de auxinas, presentan divisiones celulares conspicuas que dan origen a raíces laterales secundarias, mientras que las células de periciclo del polo del floema bajo este mismo tratamiento no dan origen a ningún órgano y presentan divisiones celulares menos conspicuas.

En la raíz existen otras estructuras especializadas, además de las raíces laterales, que pueden ser consideradas como órganos vertedero o de demanda, tales como los nódulos y las agallas que se desarrollan a partir de la infección por bacterias como Rhizobium y Agrobacterium tumefaciens y por patógenos como los nematodos. Las estructuras derivadas de la interacción de la planta con el patógeno pueden ser consideradas como órganos vertederos, dado que son sitios de alta demanda de nutrientes, ya sea para la generación y desarrollo del órgano o para el crecimiento y reproducción del patógeno.

El primer paso durante la organogénesis de un nódulo simbionte involucra la reactivación de la división de las células del periciclo en una alta tasa, lo que implica un abastecimiento masivo de nutrientes desde el floema. En Medicago se ha descrito que las células del primordio del nódulo se conectan simplásticamente al floema; una vez que ocurre la infección se ha observado un aumento en el número de plasmodesmos por unidad de área, en comparación con la zona no infectada, entre las células del periciclo y los elementos de tubo criboso adyacentes al polo del protofloema, lo que sugiere la existencia de un continuo 
simplástico entre el floema y el primordio del nódulo. La diferenciación de las células del primordio del nódulo ocurre después de la formación de este campo simplástico, por lo que es posible que sea muy importante el establecimiento de la comunicación intercelular para el transporte de las señales necesarias para la diferenciación.

La comunicación intercelular mediada por plasmodesmos entre distintas capas involucradas en la formación del nódulo ha sido también estudiada utilizando la MP del TMV. La expresión de la MP promueve un aumento en la cantidad de nódulos al incrementarse el SEL, lo que sugiere que el transporte mediado por plasmodesmos puede jugar un papel muy importante en el control de la organogénesis de dichas estructuras (Complainville et al., 2003).

Dentro de las simbiosis nodulares también se encuentran incluidas las establecidas entre actinomicetos del género Frankia y diversas especies de dicotiledóneas. En contraste con los nódulos de las leguminosas, estos nódulos están compuestos de múltiples raíces laterales modificadas que presentan un sistema vascular central y células corticales expandidas. Un estudio realizado con los nódulos de la especie Datisca glomerata reveló un incremento en la densidad de plasmodesmos desde las células más internas hacia las más externas de la corteza primaria, lo que sugiriere la formación de un continuo simplástico. En este mismo estudio se observó un mayor número de plasmodesmos entre las células maduras infectadas ya diferenciadas fijadoras de nitrógeno, en comparación con las células infectadas jóvenes, lo que implica un posible incremento en el transporte simplástico durante la diferenciación de las células infectadas (Schubert et al., 2011).

Durante la formación de estructuras de alimentación por parásitos, como los nematodos de raíz Meloidogyne incognita y Heterodera schachtii, ocurre una fuerte estimulación en la liberación de solutos desde el floema hacia los sitios de alimentación de estos parásitos. La descarga de nutrientes y otros compuestos hacia los NFS (Nematode Feeding Sites), los cuales se originan dentro del cilindro vascular, ocurre de manera específica en ciertas células de la raíz. La etapa infectiva, comúnmente reconocida como segundo estado juvenil o J2, en el caso de los nematodos que se enquistan (Heterodera spp.) y los agalladores (Meloidogyne spp.), selecciona una célula meristemática del procámbium o del cámbium vascular como una célula inicial a partir de la cual se desarrolla, ya sea un sincicio en el caso de los nematodos que se enquistan, o un grupo de células denominadas células gigantes en el caso de los agalladores. Tanto en los nematodos que se enquistan como en los agalladores, el crecimiento y desarrollo depende totalmente de la formación del sitio de alimentación. El nematodo es capaz de inducir un escape masivo de nu- trientes del floema, lo que reduce su transporte hacia otras partes de la raíz (Bellafiore y Briggs, 2010).

Estos NFS constituyen un nuevo órgano blanco desarrollado por el patógeno al modificar el desarrollo asociado posiblemente a la formación de raíz lateral por medio de la secreción de proteínas y moléculas que son capaces de simular las señales internas de las plantas. Esta hipótesis es apoyada por estudios realizados en plantas mutantes defectuosas en la morfogénesis de la raíz lateral, en las cuales ocurre el arresto en la división de las células del NFS y como consecuencia el desarrollo de la fase reproductiva de los nematodos se ve truncado (Caillaud et al., 2008) (Figura 3).

Los análisis transcriptómicos de las proteínas secretadas por el nematodo hacia la planta han permitido la identificación de péptidos involucrados en la inducción del crecimiento radicular a través de la interacción con factores de transcripción tales como SCARECROW-like, involucrados en promover la división y la diferenciación celular (Huang et al., 2006). De acuerdo con estos análisis, se han descrito al menos 1000 transcritos distintivos de las células gigantes y 547 de las agallas característicos de los nematodos agalladores, cuyos perfiles de expresión son similares a los inducidos durante la formación de agallas por Agrobacterium tumefaciens. El transporte de dichas moléculas señalizadoras a través de la ruta simplática puede ser determinante durante la infección por dichos parásitos.

De acuerdo con estudios en Impatiens balsamina, las células gigantes inducidas por $M$. incognita se aíslan simplásticamente del tejido vascular y del resto de las células vecinas mientras mantienen la comunicación entre ellas a través de plasmodesmos. En Nicotiana tabacum se describió la presencia de plasmodesmos entre las células gigantes y las células vecinas, pero se observó la presencia de calosa en estos plamodesmos, lo que sugiere la obstrucción de un continuo simplástico (Hofmann et al., 2010). En el caso de la infección por H. schachtii en Arabidopsis se ha descrito la formación de un continuo simplástico entre las células sinciciales y el floema a través de plasmodesmos con un límite de exclusión molecular de 30 kDa (Hoth et al., 2008). En Arabidopsis las células gigantes se aíslan simplásticamente, por lo que el transporte de nutrientes se lleva a cabo a través de procesos mediados por transportadores localizados en los órganos fuente, mientras que en los nematodos sinciciales los sitios de alimentación se conectan masivamente al floema a través de plasmodemos (Absmanner et al., 2013; Hoth et al., 2008).

Existen otros sitios especiales de descarga de moléculas señalizadoras y nutrientes, tales como los tubérculos. La formación de un tubérculo es un proceso denominado 

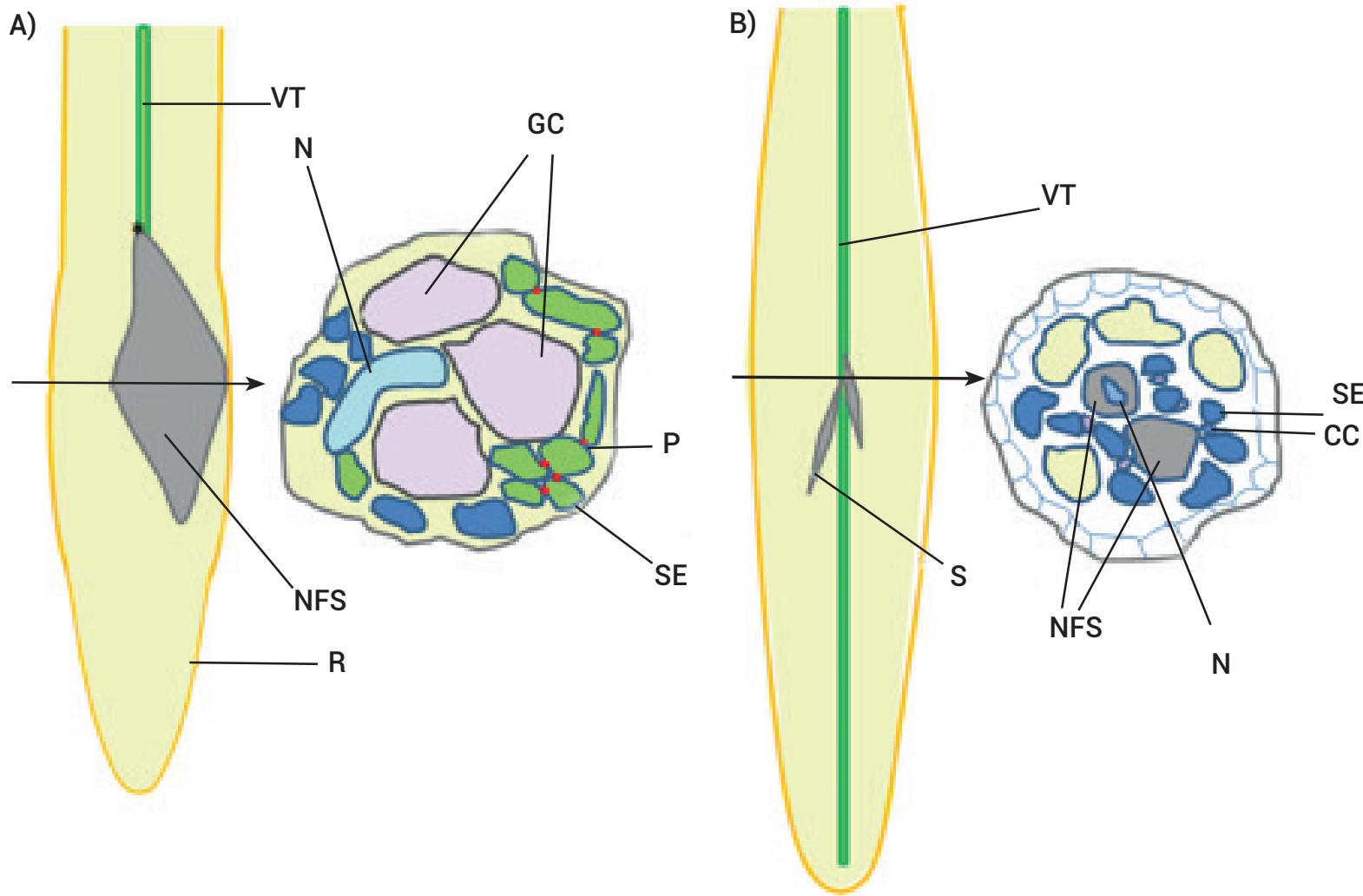

Figura 3. A) Formación de un dominio simplástico durante la infección por nematodos $(\mathrm{N})$ agalladores, cuyo sitio de alimentación (NFS) se induce a partir de varias células meristemáticas en la raíz (R), las cuales se convierten en células gigantes (GC). B) En el sincicio (S) inducido por los nematodos que se enquistan se da lugar a la formación de elementos de tubo criboso (SE) y células acompañantes (CC) interconectadas por plasmodesmos.

tuberización que involucra el establecimiento de un continuo simplástico entre el floema de descarga y el tubérculo (Viola et al., 2001). La tuberización está regulada tanto por señales externas como internas. Una de las señales externas que regula la tuberización es la longitud del día. Días cortos inducen la tuberización en Solanum tuberosum ssp. andigena, mientras que días largos inhiben este proceso (Jackson, 1999; Martínez-García et al., 2002). En plantas que forman tubérculos, los pecíolos de las hojas fuente son una región importante que constituye el sitio de conexión vascular o canal entre la lámina foliar y las señales lumínicas que determinan el transporte (Shah et al., 2011).

Dentro de las señales internas reconocidas como relevantes para la tuberización se encuentran la ruta del ácido giberélico y la movilización de mensajeros como BEL-1 like (StBEL5), el cual pertenece a una familia de factores de trascripción implicados en el mantenimiento del patrón de formación del meristemo apical del brote. StBEL 5 se mueve del tejido vascular de las hojas hacia el estolón y, junto con la proteína KNOX POTH1, media cambios en las concentraciones de ácido giberélico, entre otras hormonas (Chen et al., 2004; Rosin et al., 2003). Los cambios en las concentraciones hormonales promueven el estableci- miento del tejido de demanda o tubérculo, lo cual a su vez induce la expansión y la división celular, así como el transporte de grandes cantidades de sacarosa para la síntesis de almidón en las células subapicales del ápice del estolón.

Las plantas que sobre expresan StBEL5 presentan un aumento en la cantidad de tubérculos, mientras que las plantas que expresan una copia completa del gen que incluye ambas regiones UTR son capaces de inducir tuberización bajo condiciones de fotoperíodo largo (Chen et al., 2004; Hannapel, 2010). Como parte de las señales que regulan la formación del tubérculo se ha propuesto que el transporte de otras macromoléculas a través de los elementos de tubo criboso puede ser esencial (Shah et al., 2011).

\section{CONCLUSIONES}

La adquisición de un sistema de transporte especializado, capaz de ser regulado y modulado de manera eficaz en respuesta a señales tanto internas como externas, es un factor clave para el éxito evolutivo de las plantas. Las características del tejido vascular permiten el transporte eficiente de diversos metabolitos y la formación de redes de intercomunicación que son determinantes en la coordinación del 
crecimiento y el desarrollo de los órganos entre los cuales destacan los frutos, las semillas y aquellos formados por otros organismos parásitos o simbiontes, que funcionan como regiones de alta demanda. Son principalmente las células del floema las implicadas en la regulación del transporte durante procesos que pueden estar relacionados con el desarrollo o la respuesta a estrés biótico o abiótico; sin embargo, la formación de una red de interconexión entre el floema y el resto de los tejidos mediante estructuras especializadas, como los plasmodesmos, también resulta ser evolutivamente relevante. Actualmente, muchos estudios se enfocan en identificar y establecer la función de las proteínas y RNA que se transportan a través del floema, mientras que otros tienen como objetivo determinar el papel de las proteínas que se localizan en los plasmodesmos, con el fin de entender detalladamente los mecanismos que regulan el paso selectivo a través de la ruta simplástica. Ambas aproximaciones permitirán entender y aplicar este conocimiento a favor de la implementación de tecnología con el fin de modular el transporte de diversas moléculas implicadas en el crecimiento y desarrollo de estructuras de importancia agronómica.

\section{AGRADECIMIENTOS}

EZS agradece el apoyo recibido de DGAPA-UNAM (beca posdoctoral y financiamiento al proyecto IN214314) y los comentarios de Vera Martínez.

\section{BIBLIOGRAFÍA}

Absmanner B., R. Stadler and U. Z. Hammes (2013) Phloem development in nematode-induced feeding sites: the implications of auxin and cytokinin. Frontiers in Plant Science 4:241

Amari K., E. Boutant, C. Hofmann, C. Schmitt-Keichinger, L. Fernandez-Calvino, P. Didier, A. Lerich, J. Mutterer, C. L. Thomas, M. Heinlein, Y. Mély, A. J. Maule and C. Ritzenthaler (2010) A family of plasmodesmal proteins with receptor-like properties for plant viral movement proteins. PLoS Pathogens 6:e1001119.

Bellafiore S. and S. Briggs (2010) Nematode effectors and plant responses to infection. Current Opinion in Plant Biology 13:442-448.

Benitez-Alfonso Y., M. Cilia, A. San Roman, C. Thomas, A. Maule, S. Hearn and D. Jackson (2009) Control of Arabidopsis meristem development by thioredoxin-dependent regulation of intercellular transport. Proceedings of the National Academy of Sciences of the United States of America 106:3615-3620.

Berleth T. and J. Mattsson (2000) Vascular development: tracing signals along veins. Current Opinion in Plant Biology 3:406-411.

Bishopp A., S. Lehesranta, A. Vatén, H. Help, S. El-Showk, B. Scheres, K. Helariutta, A. P. Mähönen, H. Sakakibara and Y. Helariutta (2011) Phloem-transported cytokinin regulates polar auxin transport and maintains vascular pattern in the root meristem. Current Biology 21:927-932.

Bonke M., S. Thitamadee, A. P. Mahonen, M. T. Hauser and Y. Helariutta (2003) APL regulates vascular tissue identity in Arabidopsis. Nature 426:181-186.

Bryan A. C., A. Obaidi, M. Wierzba and F. E. Tax (2012) XYLEM INTERMIXED WITH PHLOEM1, a leucine-rich repeat receptor-like kinase required for stem growth and vascular development in Arabidopsis thaliana. Planta 235:111-122.

Burch-Smith T. M., S. Stonebloom, M. Xu and P. C. Zambrysky (2011) Plasmodesmata during development: re-examination of importance of primary, secondary, and branched plasmodesmata structure versus function. Protoplasma 248:61-74.

Caillaud M. C., P. Lecomte, F. Jammes, M. Quentin, S. Pagnotta, E. Andrio, E. de Almeida, N. Marfaing, P. Gounon, P. Abad and B. Favery (2008) MAP65-3 microtubule-associated protein is essential for-nematode-induced giant cell ontogenesis in Arabidopsis. Plant Cell 20:423-437

Caño-Delgado A., Y. Yin, C. Yu, D. Vafeados, S. Mora-García, J. C. Cheng, K. H. Nam, J. Li and J. Chory (2004) BRL1 and BRL3 are novel brassinosteroid receptors that function in vascular differentiation in Arabidopsis. Development 131:5341-5351.

Chen H., A. K. Banerjee and D. J. Hannapel (2004) The tandem complex of $\mathrm{BEL}$ and KNOX partners is required for transcriptional repression of ga20ox. The Plant Journal 38:276-284.

Chen L. Q., I. W. Lin, X. Q. Qu, D. Sosso, H. E. McFarlane, A. Londoño, A. L. Samuels and W. B. Frommer (2015) A cascade of sequentially expressed sucrose transporters in the seed coat and endosperm provides nutrition for the Arabidopsis embryo. The Plant Cell 27:607-619.

Complainville A., L. Brocard, I. Roberts, E. Dax, N. Sever, N. Sauer, A. Kondorosi, S. Wolf, K. Oparka and M. Crespi (2003) Nodule initiation involves the creation of a new symplasmic field in specific root cells of Medicago species. The Plant Cell 15:2778-2791.

De Rybel B., M. Adibi, A. S. Breda, J. Wendrich, M. E. Smit, O. Novák, N. Yamaguchi, S. Yoshida, G. V. Isterdael, J. Palovaara, B. Nijsse, M. V. Boekschoten, G. Hooiveld, T. Beeckman, D. Wagner, K. Ljung, C. Fleck and D. Weijers (2014) Integration of growth and patterning during vascular tissue formation in Arabidopsis. Science 345:1255215. doi: 10.1126/science.1255215.

Dolan L., K. Janmaat, V. Willemsen, P. Linstead, S. Poethig, K. Roberts and B. Scheres (1993) Cellular organisation of the Arabidopsis thaliana root. Development 119:71-84.

Dubrovsky J. G., P. W. Doerner, A. Colón-Carmona and T. L. Rost (2000) Pericycle cell proliferation and lateral root initiation in Arabidopsis. Plant Physiology 124:1648-1657.

Esau K. and V. I. Cheadle (1959) Size of pores and their contents in sieve elements of dicotyledons. Proceedings of the National Academy of Sciences of the United States of America 45:156-162.

Fernandez-Calvino L., C. Kaulkner, J. Walshaw, G. Saalbach, E. Bayer, J. Benitez-Alfonso and A. Maule (2011) Arabidopsis plasmodesmal proteome. PloS One 6:e18880

Fisher K. and S. Turner (2007) PXY, a receptor-like kinase essential for maintaining polarity during plant vascular-tissue development. Current Biology 17:1061-1066.

Hannapel D. J. (2010) A model system of development regulated by the long-distance transport of mRNA. Journal of Integrative Plant Biology 52:40-52.

Hardtke C. S. and T. Berleth (1998) The Arabidopsis gene MONOPTEROS encodes a transcription factor mediating embryo axis formation and vascular development. The EMBO Journal 17:14051411.

Haywood V., F. Kragler and W. J. Lucas (2002) Plasmodesmata: pathways for proteon and ribonucleoprotein signaling. The Plant Cell Supplement 2002:S303-S325.

Hejátko J., H. Ryu, G. T Kim, R. Dobešová, S. Choi, S. M. Choi, P. Souček, J. Horák, B. Pekárová, K. Palme, B. Brzobohatý and I. Hwang (2009) The histidine kinases CYTOKININ-INDEPENDENT1 and ARABIDOPSIS HISTIDINE KINASE2 and 3 regulate vascular tissue development in Arabidopsis shoots. The Plant Cell 21:2008-2021.

Hofmann J., M. Youssef-Banora, J. de Almeida-Engler and F. M. Grundler (2010) The role of callose deposition along plasmodesmata in nematode feeding sites. Molecular Plant-Microbe Interactions 23:549-557.

Hoth S., R. Stadler, N. Sauer and U. Z. Hammes (2008) Differential vascularization of nematode-induced feeding sites. Proceedings of the National Academy of Sciences of the United States of America 105:12617-12622

Huang G., R. Dong, R. Allen, E. L. Davis, T. J. Baum and R. S. Hussey (2006) A root-knot nematode secretory peptide functions as a ligand for a plant transcription factor. Molecular Plant-Microbe Interactions 19:463-470.

Ilegems M., V. Douet, M. Meylan-Bettex, M. Uyttewaal, L. Brand, J. L. Bowman and P. A. Stieger (2010) Interplay of auxin, KANADI and Class III 
HD-ZIP transcription factors in vascular tissue formation. Development 137:975-984.

Jackson S. D. (1999) Multiple signaling pathways control tuber induction in potato. Plant Physiology 119:1-8.

Kehr J. and A. Buhtz (2008) Long distance transport and movement of RNA through the phloem. Journal of Experimental Botany 59:85-92.

Kerstetter R. A., K. Bollman, R. A. Taylor, K. Bomblies and R. S. Poethig (2001) KANADI regulates organ polarity in Arabidopsis. Nature 411:706-709

Laplaze L., B. Parizot, A. Baker, L. Ricaud, A. Martinière, F. Auguy, C. Franche, L. Nussaume, D. Bogusz and J. Haseloff (2005) GAL4-GFP enhancer trap lines for genetic manipulation of lateral root development in Arabidopsis thaliana. Journal of Experimental Botany 56:2433-2442.

Lazareva E. A., A. A. Lezzhov, T. V. Komarova, S. Y. Morozov, M. Heinlein and A. G. Solovyev (2016) A novel block of plant virus movement genes. Molecular Plant Pathology 18:61 1-624.

Lee J. Y. (2014) New and old roles of plasmodesmata in immunity and parallels to tunneling nanotubes. Plant Science 221:13-20.

Lee J. Y. and H. Lu (2011) Plasmodesmata: the battleground against intruders. Trends in Plant Science 16:201-210.

Lehesranta S. J., R. Lichtenberger and Y. Helariutta (2010) Cell-to-cell communication in vascular morphogenesis. Current Opinion in Plant Biology 13:59-65.

Liu X., Y. Zhang, C. Yang, Z. Tian and J. Li (2016) AtSWEET4, a hexose facilitator, mediates sugar transport to axial sinks and affects plant development. Scientific Reports 6:24563.

Lough T. J. and W. J. Lucas (2006) Integrative plant biology: role of phloem long-distance macromolecular trafficking. Annual Review of Plant Biology 57:203-232.

Lucas W. J., B. Ding and C. van der Schoot (1993) Plasmodesmata and the supracellular nature of plants. New Phytologist 125:435-476.

Mähönen A. P., A. Bishopp, M. Hiquchi, K. M. Nieminen, K. Kinoshita, K. Törmäkangas, Y. Ikeda, A. Oka, T. Kakimoto and Y. Helariutta (2006) Cytokinin signaling and its inhibitor AHP6 regulate cell fate during vascular development. Science 311:94-98.

Mähönen A. P., M. Bonke, L. Kauppinen, M. Riikonen, P. N. Benfey and Y. Helariutta (2000) A novel two-component hybrid molecule regulates vascular morphogenesis of the Arabidopsis root. Genes \& Development 14:2938-2943.

Martínez-García J. F., A. Virgós-Soler and S. Prat (2002) Control of photoperiod-regulated tuberization in potato by the Arabidopsis flowering-time gene CONSTANS. Proceedings of the $\mathrm{Na}$ tional Academy of Sciences of the United States of America 99:15211-15216

Mongrand S., T. Stanislas, E. M. F. Bayer, J. Lherminier and F. Simon-Plas (2010) Membrane rafts in plant cells. Trends in Plant Science 15:656-663.

Mullendore D. L., C. W. Windt, H. Van As and M. Knoblauch (2010) Sieve tube geometry in relation to phloem flow. The Plant Cell 22:579-593.

Ohashi-Ito K., M. Oguchi, M. Kojima, H. Sakakibara and H. Fukuda (2013) Auxin-associated initiation of vascular cell differentiation by LONESOME HIGHWAY. Development 140:765-769.

Ohashi-Ito K., M. Saegusa, K. Iwamoto, Y. Oda, H. Katayama, M. Kojima, H. Sakakibara and H. Fukuda (2014) A bHLH complex activates vascular cell division via cytokinin action in root apical meristem. Current Biology 24:2053-2058.

Parizot B., L. Laplaze, L. Ricaud, E. Boucheron-Dubuisson, V. Bayle, M. Bonke, I. D. Smet, S. R. Poethig, Y. Helariutta, J. Haseloff, D. Chriqui, T. Beeckman and L. Nussaume (2008) Diarch symmetry of the vascular bundle in Arabidopsis root encompasses the pericycle and is reflected in distich lateral root initiation. Plant Physiology 146:140-148.

Ragni L., K. Nieminen, D. Pacheco-Villalobos, R. Sibout, C. Schwechheimer and C. S. Hardtke (2011) Mobile gibberellin directly stimulates Arabidopsis hypocotyl xylem expansion. The Plant Cell 23:1322-1336

Rinne P. L. H. and C. van der Schoot (1998) Symplasmic fields in the tunica of the shoot apical meristem coordinate morphogenetic events. Development 125:1477-1485.

Rosin F. M., J. K. Hart, H. T. Horner, P. J. Davies and D. J. Hannapel (2003) Overexpression of a knotted-like homeobox gene of potato alters vegetative development by decreasing gibberellin accumulation. Plant Physiology 132:106-117.

Sagi G., A. Katz, D. Guenoune-Gelbart and B. L. Epel (2005) Class 1 reversibly glycosylated polypeptides are plasmodesmal-associated proteins delivered to plasmodesmata via de Golgi apparatus. The Plant Cell 17:1788-1800.

Schubert M., N. K. Koteyeva, P. W. Wabnitz, P. Santos, M. Büttner, N. Sauer, K. Demchenko and K. Pawlowski (2011) Plasmodesmata distribution and sugar partitioning in nitrogen-fixing root nodules of Datisca glomerata. Planta 233:139-152.

Shah S., Y. J. Lee, D. J. Hannapel and A. G. Rao (2011) Protein profiling of the potato petiole under short day and log day photoperiods. Journal of Proteomics 74:212-230.

Simpson C., C. Thomas, K. Findlay, E. Bayer and A. J. Maule (2009) An Arabidopsis $\mathrm{GPI}$-anchor plasmodesmal neck protein with callose binding activity and potential to regulate cell-to-cell trafficking. The Plant Cell 21:581-594.

Stadler R., C. Lauterbach and N. Sauer (2005a) Cell-to-cell movement of green fluorescent protein reveals post-phloem transport in the outer integument and identifies symplastic domains in Arabidopsis seeds and embryos. Plant Physiology 139:701-712.

Stadler R., K. M. Wright, C. Lauterbach, G. Amon, M. Gahrtz, A. Feuerstein, K. J. Oparka and N. Sauer (2005b) Expression of GFP-fusions in Arabidopsis companion cells reveals non-specific protein trafficking into sieve elements and identifies a novel post-phloem domain in roots. The Plant Journal 41:319-331.

Turgeon R. and S. Wolf (2009) Phloem transport: cellular pathways and molecular trafficking. Annual Review of Plant Biology 60:207221

van Bel A. J. E. (2003) Transport phloem: low profile, high impact. Plant Physiology 131:1509-1510

van Bel A. J. E., K. Ehlers and M. Knoblauch (2002) Sieve elements caught in the act. Trends in Plant Science 7:126-132

Viola R., A. G. Roberts, S. Haupt, S. Gazzani, R. D. Hancock, G. Marmiroli, G. C. Machray and K. J. Oparka (2001) Tuberization in potato involves a switch from apoplastic to symplastic phloem unloading. The Plant Cell 13:385-398.

Werner D., N. Gerlitz and R. Stadler (2011) A dual switch in phloem unloading during ovule development in Arabidopsis. Protoplasma 248:225-235.

Wright K. M. and K. J. Oparka (1997) Metabolic inhibitors induce symplastic movement of solutes from the transport phloem of Arabidopsis roots. Journal of Experimental Botany 48:1807-1814.

Xie B. and Z. Hong (2011) Unplugging the callose plug from sieve pores. Plant Signaling and Behaviour 6:491-493.

Xu X. M. and D. Jackson (2010) Lights at the end of the tunnel: new views of plasmodesmal structure and function. Current Opinion in Plant Biology 13:684-692

Zavaliev R., G. Sagi, A. Gera and B. L Epel (2010) The constitutive expression of Arabidopsis plasmodesmal-associated class 1 reversibly glycosylated polypeptide impairs plant development and virus spread. Journal of Experimental Botany 61:131-142.

Zhang L., M. G. Garneau, R. Majumdar, J. Grant and M. Tegeder (2015) Improvement of pea biomass and seed productivity by simultaneous increase of phloem and embryo loading with amino acids. The Plant Journal 81:134-146. 
